\title{
Heterozygous TREX1 mutations in early-onset cerebrovascular disease
}

\author{
N. Pelzer $\cdot$ B. de Vries $\cdot$ E. M. J. Boon • \\ M. C. Kruit · J. Haan - M. D. Ferrari • \\ A. M. J. M. van den Maagdenberg • G. M. Terwindt
}

Received: 11 July 2013/Accepted: 12 July 2013/Published online: 24 July 2013

(C) Springer-Verlag Berlin Heidelberg 2013

\section{Dear Sirs,}

We report on 100 patients suspected of cerebral autosomal dominant arteriopathy with subcortical infarcts and leukoencephalopathy (CADASIL) [1] who were analyzed in our international CADASIL referral center, but in whom no NOTCH3 mutations were found. TREXI was considered an excellent next disease gene candidate because of its link with Aicardi-Goutières syndrome (AGS) [3], the small vessel disease retinal vasculopathy and cerebral leukodystrophy (RVCL) [8], and (neuropsychiatric) systemic lupus erythematosus (SLE) [4-6]. Screening of our patient cohort yielded heterozygous TREXI mutations in two patients

\section{N. Pelzer · J. Haan · M. D. Ferrari ·}

A. M. J. M. van den Maagdenberg - G. M. Terwindt ( $\square)$ Department of Neurology, Leiden University Medical Center, Albinusdreef 2, PO Box 9600, 2300 RC Leiden, The Netherlands e-mail: g.m.terwindt@lumc.nl

N. Pelzer

e-mail: n.pelzer@lumc.nl

B. de Vries - A. M. J. M. van den Maagdenberg Department of Human Genetics, Leiden University Medical Center, Albinusdreef 2, PO Box 9600, 2300 RC Leiden,

The Netherlands

E. M. J. Boon

Department of Clinical Genetics, Leiden University Medical Center, Albinusdreef 2, PO Box 9600, 2300 RC Leiden,

The Netherlands

\section{C. Kruit}

Department of Radiology, Leiden University Medical Center, Albinusdreef 2, PO Box 9600, 2300 RC Leiden, The Netherlands

\section{J. Haan}

Department of Neurology, Rijnland Hospital, Simon Smitweg 1, PO Box 4220, 2350 CC Leiderdorp, The Netherlands with early-onset cerebrovascular disease. This expands the clinical spectrum of diseases associated with TREXI mutations, and offers a differential diagnosis for CADASIL-like phenotypes.

Patient A, a 53-year-old woman with a history of hypertension, hyperlipidemia and alcohol abuse presented with otherwise unexplained presenile dementia. MRI demonstrated basal ganglia and pontine lacunar infarcts and bilateral confluent white matter lesions (Fig. 1a-c). An extensive analysis for causes of dementia and stroke, including serum autoantibodies (ANCA, ANA) was negative. Her severe retinopathy was labeled as hypertensive. Severely demented, she died at the age of 55 of an aspiration pneumonia. Direct sequencing of the TREXI gene detected a heterozygous mutation c.1079A $>$ G; p.Tyr360Cys (p.Tyr305Cys on TREX1 isoform B).

Patient B, a 42-year-old heavily smoking man with a past medical history including a splenic artery aneurysm at age 29, hypertension, hyperlipidemia and vascular claudication presented with progressive cognitive dysfunction. His family history was positive for (cardio)vascular disease. MRI showed a cortico-subcortical infarct in the right frontal lobe, ischemic lesions in the basal ganglia, brainstem and corpus callosum, and focal T2 white matter hyperintensities (Fig. 1d-f). Extensive diagnostic work-up did not reveal other causes for his cognitive decline. CSF showed a mononuclear pleocytosis with normal protein levels, but angiography was not suggestive of a cerebral vasculitis. CSF culture was negative and serum autoantibodies (ANCA, ANA, cardiolipines) were absent.

$\mathrm{He}$ had a deep venous thrombosis in the leg at age 44. At age 46 and 47 he suffered from new brainstem infarcts. Direct sequencing detected a heterozygous TREXI mutation c.506G $>$ A; p.Arg169His (p.Arg114His on TREX1 isoform B). 

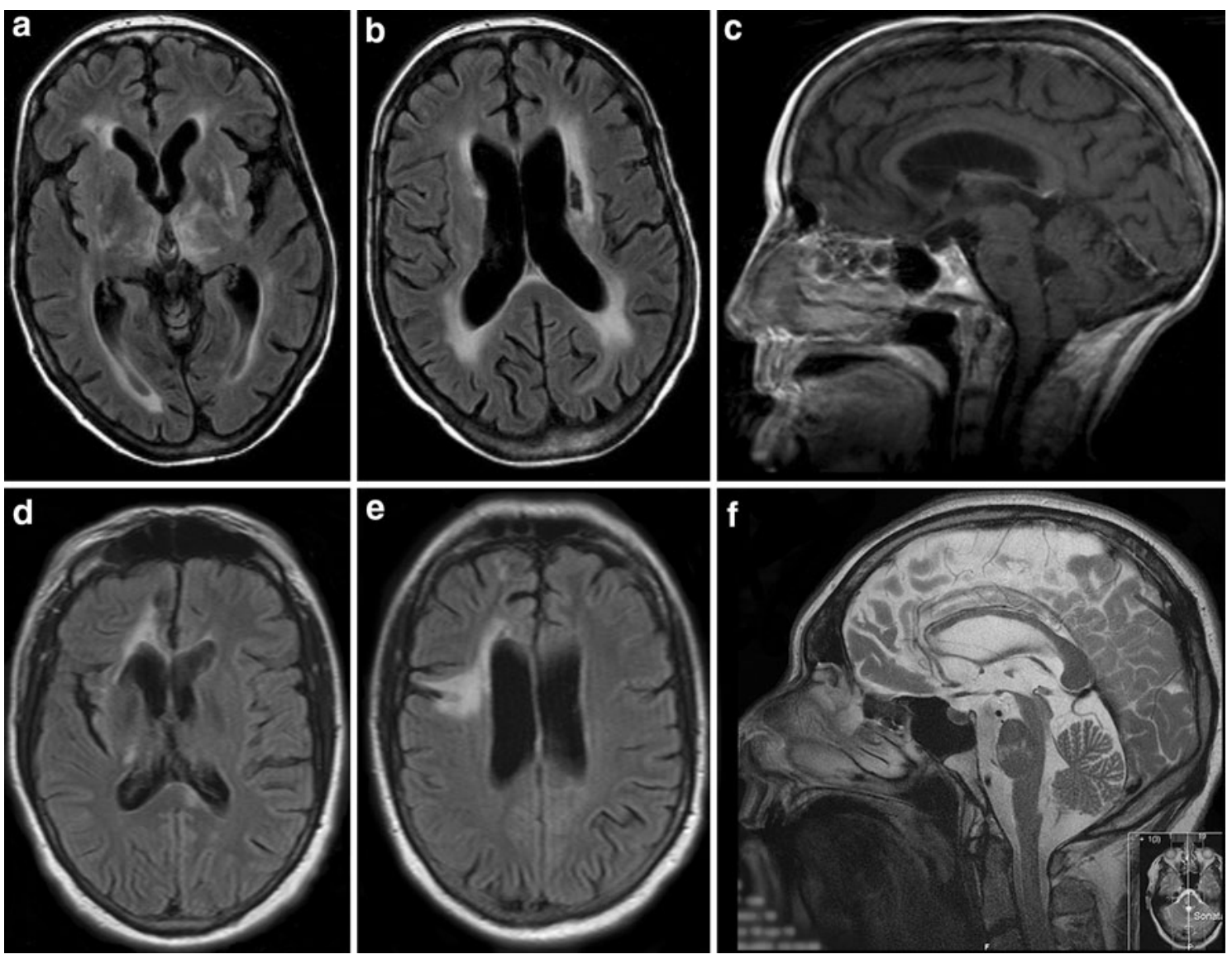

Fig. 1 a-c Axial FLAIR MRIs and sagittal T1-weighted MRI of patient $A$ at age 53 show signs of lacunar infarcts in the basal ganglia, bilateral periventricular white matter lesions, and a pontine infarct;

The two patients described were referred for CADASIL screening because of extensive white matter hyperintensities and infarcts and progressive early-onset (cerebro)vascular disease. No NOTCH3 mutations were found. Screening of the TREX1 gene revealed heterozygous mutations p.Tyr305Cys and p.Arg114His, which were both previously reported in SLE patients $[5,6]$. The p.Tyr305Cys mutation affects a highly conserved residue and was not found in large cohorts of healthy controls [5, 6]. The heterozygous p.Arg114His mutation, however, has also been identified in six controls [5, 6]. Nonetheless, when homozygous, this mutation is quite common in AGS $[2,5]$. Mutation p.Arg114His affects a highly conserved residue in the catalytic domain of TREX1 and severely decreases enzymatic activity, suggesting pathogenicity [5,7]. Enzymatic activity was also (mildly) decreased when co-expressed with wildtype TREX1 protein, mimicking the situation in heterozygotes [7]. Mutated TREX1 protein seems to cause accumulation of cytosolic nucleic acids and subsequent abnormal innate immune responses, which may have damaging effects on the circulatory system [2].

Clinical features and MRI abnormalities in our patients were not suggestive of RVCL or AGS. Absent d-f Axial FLAIR MRIs and sagittal T2-weighted MRI of patient B at age 47 show right frontal, basal ganglia, brainstem and corpus callosum infarcts

autoantibodies made SLE unlikely. Nevertheless, we hypothesize that TREXI mutations may have caused these phenotypes with adult onset. Even the phenomena referred to as 'vascular risk factors' may be part of the phenotypic spectrum of TREX1 mutations.

We suggest that early-onset cerebrovascular disease can be caused by heterozygous TREXI mutations. Further elucidation of pathogenetic mechanisms of TREXI mutations may reveal new cerebrovascular disease mechanisms.

Acknowledgments This work was supported by the European Union Seventh Framework Programme grant agreement number 241779 (NIMBL: http://www.NIMBL.eu/) (A.M.J.M.v.d.M). They had no role in the design and conduct of the study, the collection, management, analysis, and interpretation of the data, nor in the preparation, review, or approval of the manuscript.

Conflicts of interest On behalf of all authors, the corresponding author states that there is no conflict of interest.

Ethical standard This study has been performed in accordance with the ethical standards laid down in the 1964 Declaration of Helsinki. 


\section{References}

1. Chabriat H, Joutel A, Dichgans M, Tournier-Lasserve E, Bousser MG (2009) Cadasil. Lancet Neurol 8:643-653

2. Chahwan C, Chahwan R (2012) Aicardi-Goutieres syndrome: from patients to genes and beyond. Clin Genet 81:413-420

3. Crow YJ, Hayward BE, Parmar R, Robins P, Leitch A, Ali M, Black DN, van Bokhoven H, Brunner HG, Hamel BC, Corry PC, Cowan FM, Frints SG, Klepper J, Livingston JH, Lynch SA, Massey RF, Meritet JF, Michaud JL, Ponsot G, Voit T, Lebon P, Bonthron DT, Jackson AP, Barnes DE, Lindahl T (2006) Mutations in the gene encoding the $3^{\prime}-5^{\prime}$ DNA exonuclease TREX1 cause Aicardi-Goutieres syndrome at the AGS1 locus. Nat Genet 38:917-920

4. de Vries B, Steup-Beekman GM, Haan J, Bollen EL, Luyendijk J, Frants RR, Terwindt GM, Van Buchem MA, Huizinga TW, van den Maagdenberg AM, Ferrari MD (2010) TREX1 gene variant in neuropsychiatric systemic lupus erythematosus. Ann Rheum Dis 69:1886-1887

5. Lee-Kirsch MA, Gong M, Chowdhury D, Senenko L, Engel K, Lee YA, de Silva U, Bailey SL, Witte T, Vyse TJ, Kere J, Pfeiffer C, Harvey S, Wong A, Koskenmies S, Hummel O, Rohde K, Schmidt RE, Dominiczak AF, Gahr M, Hollis T, Perrino FW, Lieberman J, Hübner N (2007) Mutations in the gene encoding the $3^{\prime}-5^{\prime}$ DNA exonuclease TREX1 are associated with systemic lupus erythematosus. Nat Genet 39:1065-1067
6. Namjou B, Kothari PH, Kelly JA, Glenn SB, Ojwang JO, Adler A, Alarcon-Riquelme ME, Gallant CJ, Boackle SA, Criswell LA, Kimberly RP, Brown E, Edberg J, Stevens AM, Jacob CO, Tsao BP, Gilkeson GS, Kamen DL, Merrill JT, Petri M, Goldman RR, Vila LM, Anaya JM, Niewold TB, Martin J, Pons-Estel BA, Sabio JM, Callejas JL, Vyse TJ, Bae SC, Perrino FW, Freedman BI, Scofield RH, Moser KL, Gaffney PM, James JA, Langefeld CD, Kaufman KM, Harley JB, Atkinson JP (2011) Evaluation of the TREX1 gene in a large multi-ancestral lupus cohort. Genes Immun $12: 270-279$

7. Orebaugh CD, Fye JM, Harvey S, Hollis T, Perrino FW (2011) The TREX1 exonuclease R114H mutation in Aicardi-Goutieres syndrome and lupus reveals dimeric structure requirements for DNA degradation activity. J Biol Chem 286:40246-40254

8. Richards A, van den Maagdenberg AM, Jen JC, Kavanagh D, Bertram P, Spitzer D, Liszewski MK, Barilla-Labarca ML, Terwindt GM, Kasai Y, McLellan M, Grand MG, Vanmolkot KR, de Vries B, Wan J, Kane MJ, Mamsa H, Schäfer R, Stam AH, Haan J, de Jong PT, Storimans CW, van Schooneveld MJ, Oosterhuis JA, Gschwendter A, Dichgans M, Kotschet KE, Hodgkinson S, Hardy TA, Delatycki MB, Hajj-Ali RA, Kothari PH, Nelson SF, Frants RR, Baloh RW, Ferrari MD, Atkinson JP (2007) C-terminal truncations in human $3^{\prime}-5^{\prime}$ DNA exonuclease TREX1 cause autosomal dominant retinal vasculopathy with cerebral leukodystrophy. Nat Genet 39:1068-1070 